\title{
Development of Web-Based Module Programming Basics Lesson In X Class Vocational High School For Software Engineering Expertise Program
}

\author{
Rhd. Arqom Ahmadi Dwiloka ${ }^{1}$, Syaad Patmanthara ${ }^{2}$, Aji Prasetya Wibawa ${ }^{3}$ \\ Information Engineering Education, State University of Malang \\ arqom23@gmail.com, patmanthara@gmail.com, aji.prasetya.ft@um.ac.id
}

\begin{abstract}
Basic computer programming is one of the subjects that is applied to the $\mathrm{X}$-class department Software Engineering as the basis for the development of advanced programming. On subjects basic programming there are some basic competencies include understanding and skills. Research and development is intended to produce a product of web based modules that can be accessed using smartphones and computers to support teaching and learning in State Vocational High School in Malang, for basic programming modules can be applied to the Department of Software Engineering. The Research and development is a type of research Research \& Development (R\&D). The method used in this research and development is the methods of research and development by Sugiyono. Procedure development : (1) Potential and Problems; (2) Data Collection; (3) Product Design; (4) Validate Design; (5) Revised Design; (6) Test Product; (7) Revision products; (8) Trial Usage; (9) Revision of the Product; (10) Mass Production. The results of the research are the development of the Basic programming module on the subjects of basic computer programming class $X$.
\end{abstract}

Keywords-module, development, basic programming.

\section{INTRODUCTION}

Basic programming is one of the subjects found in the group of interest and incorporated in the specialization of $\mathrm{C} 1$ in SMK. The basic programming is applied to the $\mathrm{X}$ class of Software Engineering majors (RPL) as the basic for advanced programming development that has some basic competencies covering comprehension and skills. Programming is the process of making computer software by implementing algorithms and data structures using a particular programming language.

The programming language is the commands that are entered into the computer using a separate language that can be understood by the computer [1]. The programming language used in the learning process of basic programming is the $\mathrm{C} / \mathrm{C}$ ++ language.

The conclusion of observation result in Vocational High School (SMK) through interview with basic programming subject teacher is the interest of students in basic programming subjects is still not maximal even though students have active role in learning process that impact on students result.
For the knowledge aspect, based on the result of the class assessment, the value of the student tends to be slightly above the Minimum Exhaustiveness Criteria (KKM), 76 out of 75 . The skill aspect, average students get better result from the knowledge aspect those are above 80 .This development aims to develop web-based module teaching materials that can be accessed using a device owned by students, tailored to the curriculum of 2013 to support learning activities in schools.

Completeness of the contents of the modules that fit the curriculum and easy to use can make the students self-learning according to their ability and speed in the learning process with or without guidance from teacher. The module is a form of teaching material that is packed intact and systematic, containing a set of planned learning experiences and designed to help student's master specific learning objectives [2]. The development model used is Research \& Development (R \& D) research [3].

The previous development [4] shows that there are still some of lacks. The development of the printed module, students are still constrained in access or use, if the students accidentally forget to bring the module in the form of books then the students will have difficulty to follow the learning process because they do not have a handouts. It caused the learning process will be not maximum.

Visualization of basic programming algorithms given to students in the form of visualization files in the media Compact Disk (CD) or in Flash Drive (FD). If in the learning process students do not have the file then the lesson will be not maximum. In addition, flash visualization media require students to install supporting applications to open the media.

The development of web-based modules on basic programming subjects can supports prior development in the form of increasingly facilitated student access. With the availability of internet services during the learning process in class, students can access the material in the form of modules and visualization without constraints. In addition, this development can also facilitate teachers if unable to attend in the learning process because students can learn independently by directly opening the basic programming module based using the device they have. 
The development model selected in this development is Sugiyono (R\&D) development model because of the suitability of the model with the research developed. This suitability is based on a clear development stage in the development steps presented. The Research and Development (R \& D) model has 3 stages of revision and 2 stages of testing to be performed. Based on this, the basic web-based programming module to be developed can meet expectations.

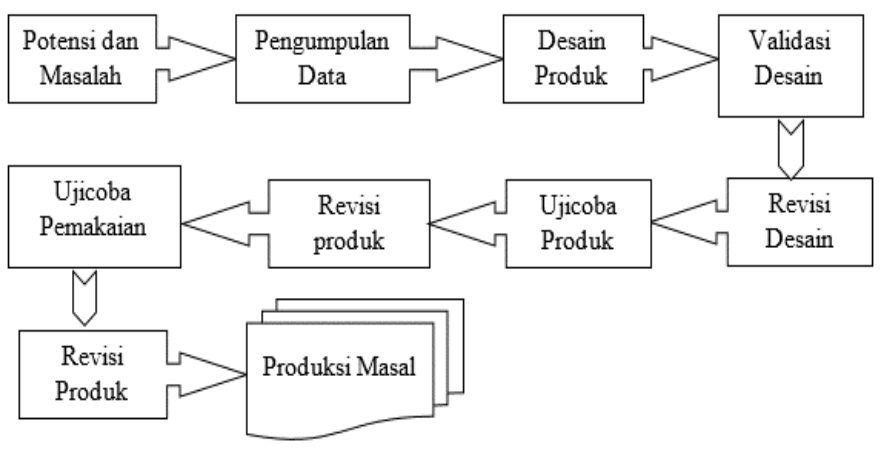

Fig. 1. Sugiyono development measures.

\section{METHODOLOGY}

Strategy is a plan, step, and sequence to achieve a goal, in learning educators must make a plan, steps in achieving goals [4]. While the method is the way used to implement strategy [5]. Learning strategies and methods should encourage students to move according to their learning style [5]. In other words strategy is a plan to achieve a goal while the method is a way to achieve that goal. Learning strategy used in developing this module using Problem Based Learning (PBL) strategy.

Problem Based Learning is a learning approach that helps students to find the problem of a real event, gathering information through a predetermined strategy to achieve problem solving [6].

The research method used in the development of this basic programming module is research and development method by Sugiyono (2010). The steps of development are:

\section{Potential and Problems}

This stage is used to identify potentials and problems related to basic programming subjects that use the 2013 curriculum, Schools still require the development of learning support such as modules to achieve established core competencies. The lack of modules for these subjects in SMK through further development, the basic programming materials are expected to be accepted by students well and can exceed the standard.

\section{Data colection}

Data collection is done as a material or a basis for designing and building the basic programming module that is expected to be a solution to improve the understanding of students. The materials collected to be the basis for making appropriate modules are syllabuses, reference books used by basic programming subject teachers and other supporting data.
The data collection that will support the module making is done in the RPL department in SMK for the first semester.

\section{Product Design}

The developed modules contain materials and evaluations that are tailored to the content of the basic programming syllabus. Competence developed in the module is a competence for the basic programming subjects of RPL class $\mathrm{X}$. Compatibility of the contents with the competencies developed supported by an interesting design so as to increase the interest of students in the learning process.

\section{Design Validation}

Design validation is a process to assess the design of the module development to determine the extent of content and design compliance and to know the advantages and disadvantages of the product so that the quality and suitability of the product to be used in the process of learning. Validation is performed by experts in accordance with their competence in the development of basic programming module products.

\section{Design Revision}

Revision or design improvements can be made after known deficiencies contained in the product in the form of modules through expert validation process. Furthermore, these deficiencies serve as reference for improving the product design so as to produce a viable module.

\section{Product Trial}

After the validation and design revision process, the product samples in the form of a basic programming module can be tested in small groups to find out how the products are used by students.

Trial in this development by conducting questionnaires for design validation to materials experts and media experts as well as testing on students as product development targets.

The subjects of the trial are those who validate the product of the developed instructional materials:

a. Media expert is a lecturer of Informatics Engineering Education Study Program

b. A material expert is a teacher of basic programming subjects in SMK.

c. Students' class X majors RPL in SMK.

The types of data used in this development are qualitative and quantitative data. Qualitative data obtained from responses or suggestions from material experts, media experts and students of the product, while the quantitative data obtained through the value of a questionnaire that has been disseminated.

\section{Produk Revision}

The results of testing product samples in small groups can indicate the feasibility of the module is appropriate or not with the students, in this case whether the product can be said "quite valid" or "very valid". After knowing the feasibility level of small group trial it is necessary to re-adjust the product made to 
increase the participant interest and convenience in using the module.

\section{Trial Use}

Trial of product use on a larger scale is done after product revision based on small-scale trials. The trial involved about 40 students (one class). By giving a questionnaire as in the previous trial.

\section{Product Revision}

After the trial use, must be refined product of the basic programming module based on the results of large-scale test. Improvement or revision of this product aims to get the results of the learning module in accordance with the demands of learning objectives that can help the learning process of students in SMK.

In this stage is also done data processing test results using data analysis techniques in accordance with the data obtained. After all data from the respondents collected through the next questionnaire will be analyzed by qualitative and quantitative data analysis techniques. Qualitative and quantitative data obtained will then be processed to obtain results about the feasibility of the product developed to determine the next process.

\section{Mass Production}

Mass production in this basic web-based programming module is done to disseminate information or access to students in SMK as one of the handles for basic programming learning process.

\section{Maintaining the Integrity of the Specifications}

The template is used to format your paper and style the text. All margins, column widths, line spaces, and text fonts are prescribed; please do not alter them. You may note peculiarities. For example, the head margin in this template measures proportionately more than is customary. This measurement and others are deliberate, using specifications that anticipate your paper as one part of the entire proceedings, and not as an independent document. Please do not revise any of the current designations.

\section{RESULTS AND DISCUSSION}

Through the module development will be obtained the results of a basic website-based programming module that can facilitate students in the learning process. The module contains several sections

\section{A. Main Page}

The main page has several sections: Header, Media Logo, Home menu, Material menu, simulation menu, About Us menu, Support menu, Entry / Exit, Profile menu and content page. Main page view corresponds to Fig. 2.

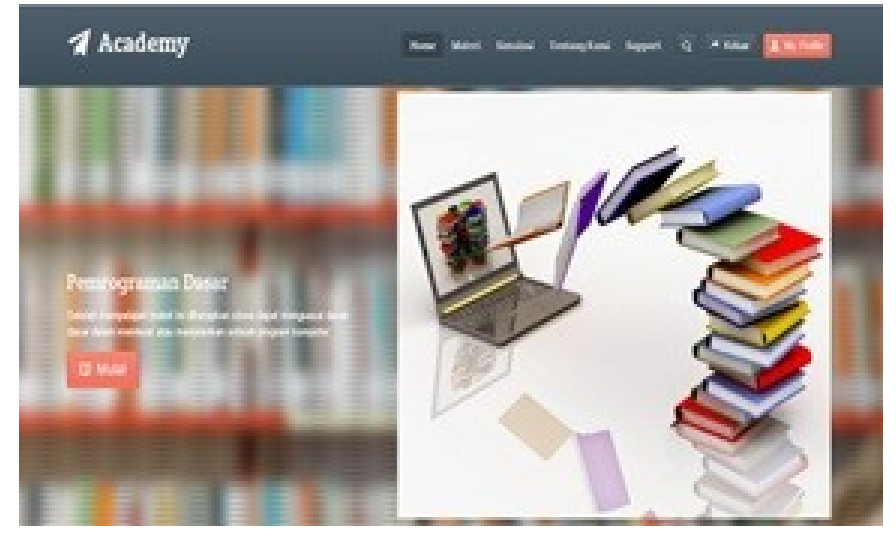

Fig. 2. main page

\section{B. Pages of Material}

This page contains the same menu as on the main page, but there are some parts that distinguish the main page. The page will displays the materials contained on the subjects of the basic programming that consists of Basic Programming Algorithm, Algorithm Recurrence, branching algorithms and programming languages. Page views as shown in Fig. 3.
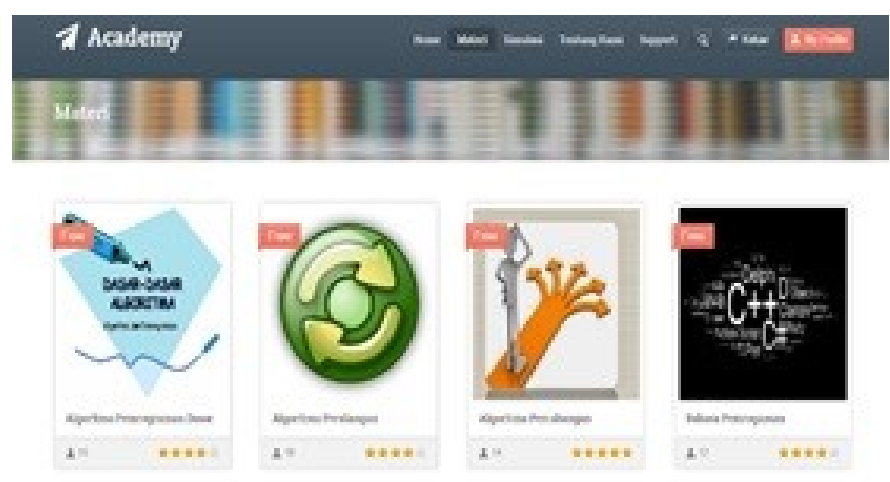

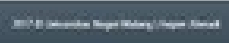

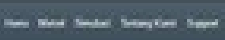

Fig. 3. material pages

Every material that displayed on the material menu, there is a sub-material that will explain the contents of the material in more detail. In addition, in each sub-material will be given additional either video or slide presentation as an aid for students in understanding the material.

\section{Evaluation Page}

The page displays the evaluation content according to the sub-material selected by the user. The evaluation content will be tailored to the materials that already learned in the previous material menu as shown in Fig. 4. 


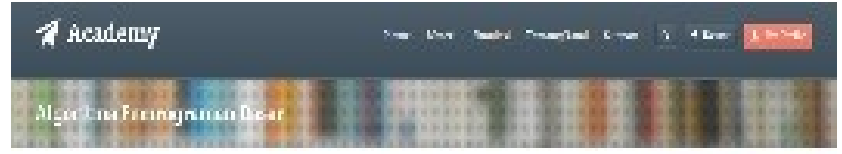

Sireplinor $; b$

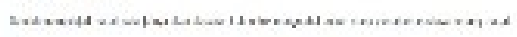

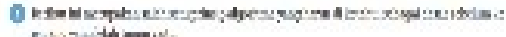

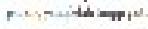

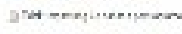

ahimensu

$3 \times$

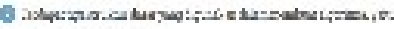

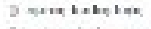

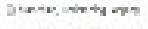

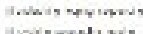

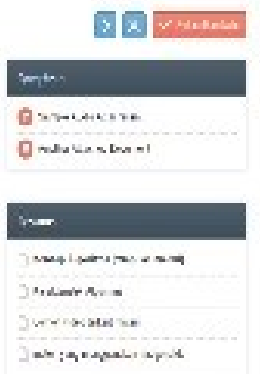

Fig. 4. Evaluation Page

\section{CONCLUSION}

Validation has been implemented with 2 material experts and media experts. The results for the development of this module are eligible for use.

The development of modules using the development model of Sugiyono is a solution to the learning process and can improve the learning results of students in basic programming subjects. Students can learn more maximally with easier material access which will impact on better learning results.

The development still has many of lacks, therefore it still needs further development in order to obtain better results.

\section{REFERENCES}

[1] G. Eason, B. Noble, and I.N. Sneddon, "On certain integrals of Lipschitz-Hankel type involving products of Bessel functions," Phil. Trans. Roy. Soc. London, vol. A247, pp. 529-551, April 1955. (references)

[2] J. Clerk Maxwell, A Treatise on Electricity and Magnetism, 3rd ed., vol. 2. Oxford: Clarendon, 1892, pp.68-73.

[3] I.S. Jacobs and C.P. Bean, "Fine particles, thin films and exchange anisotropy," in Magnetism, vol. III, G.T. Rado and H. Suhl, Eds. New York: Academic, 1963, pp. 271-350.

[4] K. Elissa, "Title of paper if known," unpublished.

[5] R. Nicole, "Title of paper with only first word capitalized," J. Name Stand. Abbrev., in press.

[6] Y. Yorozu, M. Hirano, K. Oka, and Y. Tagawa, "Electron spectroscopy studies on magneto-optical media and plastic substrate interface," IEEE Transl. J. Magn. Japan, vol. 2, pp. 740-741, August 1987 [Digests 9th Annual Conf. Magnetics Japan, p. 301, 1982].

[7] M. Young, The Technical Writer's Handbook. Mill Valley, CA: University Science, 1989. 